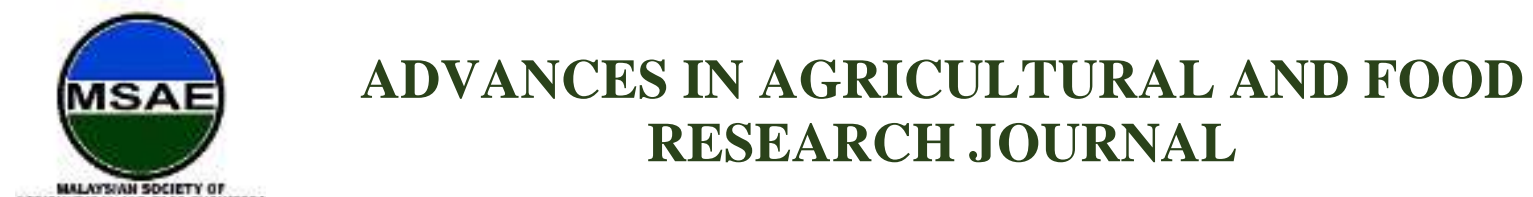

Original Research Paper

\title{
Mechanical Static Structural Analysis of CANTAS Sickle Blade
}

\author{
Ahmad Syazwan Ramli ${ }^{*}$, Abd Rahim Shuib ${ }^{1}$, Mohd Azwan Mohd Bakri ${ }^{1}$, Mohd Ikmal Hafizi Mohd \\ Azaman ${ }^{1}$, Mohd Khairul Fadzly Md Radzi ${ }^{1}$, Mohd Rizal Ahmad ${ }^{1}$, Mohd Ramdhan Mohd Khalid ${ }^{1}$, Salmah \\ Jahis $^{1}$ \\ ${ }^{1}$ Farm Mechanization Centre, Stesen Penyelidikan Usahasama MPOB/UKM, Jalan Sekolah, Pekan Bangi \\ Lama, 43000 Kajang, Selangor, Malaysia \\ **Corresponding author: Ahmad Syazwan Ramli, Farm Mechanization Centre, Stesen Penyelidikan \\ Usahasama MPOB/UKM, Jalan Sekolah, Pekan Bangi Lama, 43000 Kajang, Selangor, Malaysia; \\ ahmad.syazwan@mpob.gov.my
}

\begin{abstract}
A CANTAS is a motorized palm tree cutter which is specially developed to ease the process of harvesting oil palm fresh fruit bunch (FFB). The most crucial part of this machine is the top sickle which is vibrated by the help of a motor to facilitate the cutting process. The current sickle design is made out of AISI 5160 high carbon spring steel. This paper investigates the static structural strength of the sickle by analyzing it using a Finite Element (FEM) simulation software. The mechanical structural properties of the sickle blade material are compared with A6061-T6 aluminum alloy and AISI 316 stainless steel in the software. The result of the analysis showed that spring steel has the least structural deformation when subjected under $300 \mathrm{~N}$ of cutting force which is only $6.42 \mathrm{~mm}$ compared to $6.98 \mathrm{~mm}$ by stainless steel and $18.94 \mathrm{~mm}$ by aluminum. The total stress experienced by the sickle made of spring steel, stainless steel and aluminum are $672 \mathrm{MPa}, 671 \mathrm{MPa}$ and $668 \mathrm{MPa}$ respectively. Although spring steel sickle experiences the highest stress, the value does not exceed its ultimate tensile strength value which means that it will not break under such stress, unlike stainless steel and aluminum. In terms of weight, aluminum sickle is the lightest which is only $70.25 \mathrm{~g}$ when applied to the current design compared to $199.58 \mathrm{~g}$ for spring steel and $202.88 \mathrm{~g}$ for stainless steel. However, the disadvantage of spring steel compared to the other two materials is that the spring steel is prone to corrosion due to rust. In conclusion, the current material for the sickle design which is spring steel is the best choice of material for CANTAS when compared to aluminum and stainless steel based on the analysis done using FEM simulation.
\end{abstract}

Keywords: Oil palm fruit bunch; cutting machine; FEM analysis; material properties; metal strength

Received: $13^{\text {th }}$ May 2020

Accepted: $11^{\text {th }}$ June 2020

Citation: Ramli AS, Shuib AR, Mohd Bakri MA, et al. Mechanical static structural analysis of CANTAS

Published: $26^{\text {th }}$ June 2020 sickle blade. Adv Agri Food Res J 2020; 1(1): a0000095. https://doi.org/10.3687/aafrj.a0000095 


\section{Introduction}

The oil palm industry is the biggest plantation commodity in Malaysia. It is also the second biggest palm oil producer in the world (Kushairi et al., 2019). However, this industry still relies on traditional harvesting method which is using a sickle attached to a long pole. There is a need to develop an efficient harvesting method so that the harvesting cycle can be done within the required timeframe which is about 10 to 12 days intervals. Currently, the manual harvesting either using a sickle or the chisel is only able to produce 1 ton of fresh fruit bunch (FFB) of oil palm per man per day on average (Ismail et al., 2015). Therefore, a better harvesting system is required to harvest the FFB in a more efficient way.

Malaysian Palm Oil Board (MPOB) has developed a new system of harvesting FFB by using a motorized oil palm cutter which vibrates the sickle in order to ease and make the cutting process faster and efficient. This technology is known as CANTAS and has been developed since 2007 as shown in Figure 1 (Jelani et al., 2008).

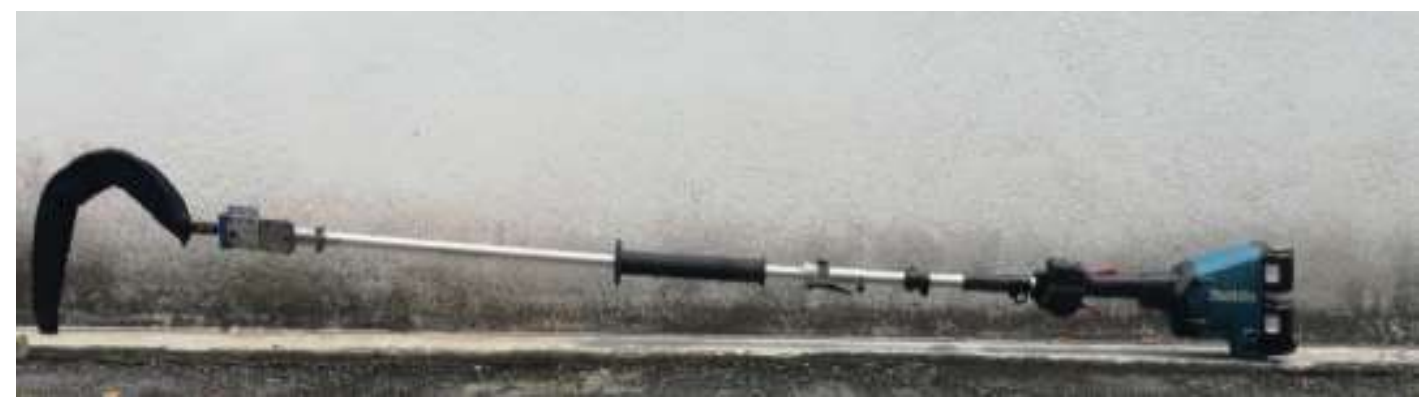

Figure 1. A motorized oil palm cutter or CANTAS which was developed by MPOB.

Although CANTAS technology has been widely accepted by the oil palm industry, there is a lot of opportunities to further improve this technology so that it can be optimized and its performance can be further improved. This paper analyses the material of CANTAS's sickle part in terms of its suitability by comparing the material properties against other metals such as aluminum and stainless steel.

\section{Materials and Methods}

\subsection{Material selection}

The sickle part of CANTAS is made out of AISI 5160 high carbon steel or widely known as spring steel. This steel grade is the most common material used for a cutting tool such as sickle, short knife and machete in the agriculture sector. It consists of high carbon chromium alloy with maximum carbon content $0.61 \%$ and chromium content which is around $0.9 \%$. It has excellent toughness, ductility and fatigue resistance. It is also used in industrial applications such as the automotive sector for various heavy-duty spring applications (The Material World, 2020). That is the reason why this steel grade is commonly known as spring steel.

The performance of spring steel material of CANTAS sickle is compared with AISI 316 stainless steel and A6061-T6 aluminum alloy. Stainless steel is chosen due to its hardness and non-corrosive characteristic which is the main reason why this material is often used to 
make kitchen utensils such as spoon, fork and knives. Aluminum, on the other hand, is not only chosen for its non-corrosive characteristic, but also for its lightweight characteristic. Weight of the sickle plays an important aspect because if the sickle is heavy, the stability of CANTAS is jeopardized during its operation. The extra load due to a heavy sickle will cause difficulty for the CANTAS operator to maneuver during the oil palm FFB harvesting process. Table 1 below summarizes the material properties of 3 chosen materials for this analysis.

Table 1. Material properties comparison for spring steel, stainless steel and aluminum.

\begin{tabular}{cccc}
\hline Material & Density $(\mathrm{g} / \mathrm{cm} 3)$ & $\begin{array}{c}\text { Tensile ultimate } \\
\text { strength }(\mathrm{MPa})\end{array}$ & Source \\
\hline $\begin{array}{c}\text { AISI 5160 } \\
\text { Spring Steel }\end{array}$ & 7.85 & 1025 & $\begin{array}{c}\text { (The Material } \\
\text { World, 2020) }\end{array}$ \\
$\begin{array}{c}\text { AISI Stainless } \\
\text { Steel 316 }\end{array}$ & 8.03 & 515 & $\begin{array}{c}\text { (The World } \\
\text { Material, 2020) }\end{array}$ \\
$\begin{array}{c}\text { A6061-T6 } \\
\text { Aluminum alloy }\end{array}$ & 2.70 & 310 & (MakeItFrom.com, \\
2020)
\end{tabular}

\subsection{Analysis method}

The comparison of the mechanical properties analysis between the 3 chosen materials is done by using a finite element method (FEM) simulation. In this analysis, FEM simulation predicts the structural mechanical behavior of the component based on the assigned physical phenomenon, loads and physical shape design via mathematical partial differential equations (Harish, 2019). Before running the simulation, a 3D computer-aided drawing (CAD) of CANTAS sickle needs to be prepared and uploaded into simulation software such as ANSYS. The sickle has a thickness of $1.2 \mathrm{~mm}$ and its dimension is shown in Figure 2.

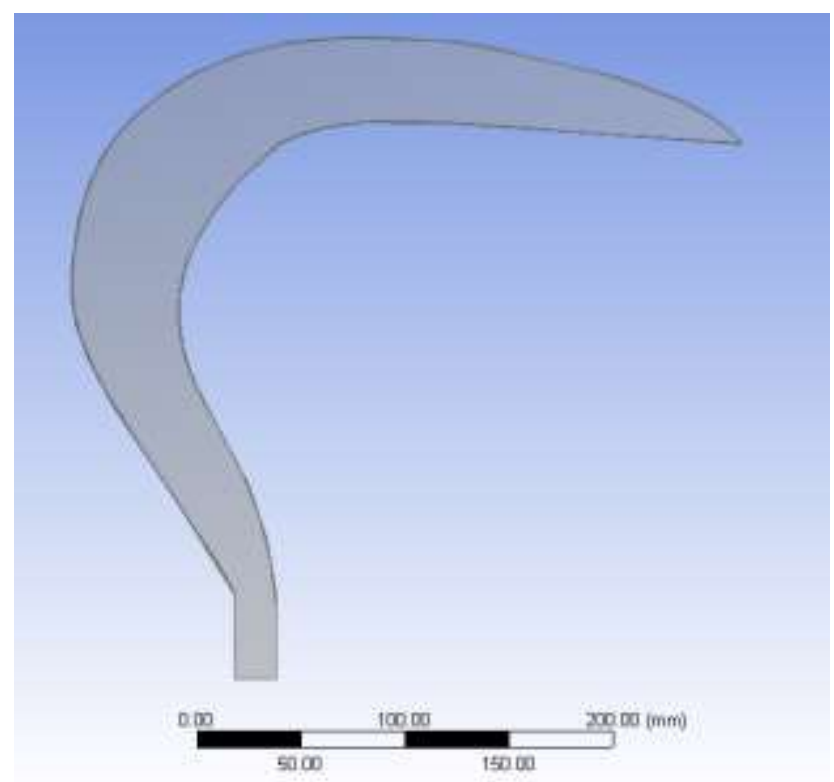

Figure 2. A 3D CAD design of CANTAS sickle. 
In this software, the sickle is converted into small elements by using mesh generation tool. This enables the software to assign FEM algorithm to each and every element of the sickle design so that the computational tool in the software can perform engineering analysis to the sickle design. The mesh generation has divided the sickle CAD design into 63262 elements with 130159 nodes as shown in Figure 3.

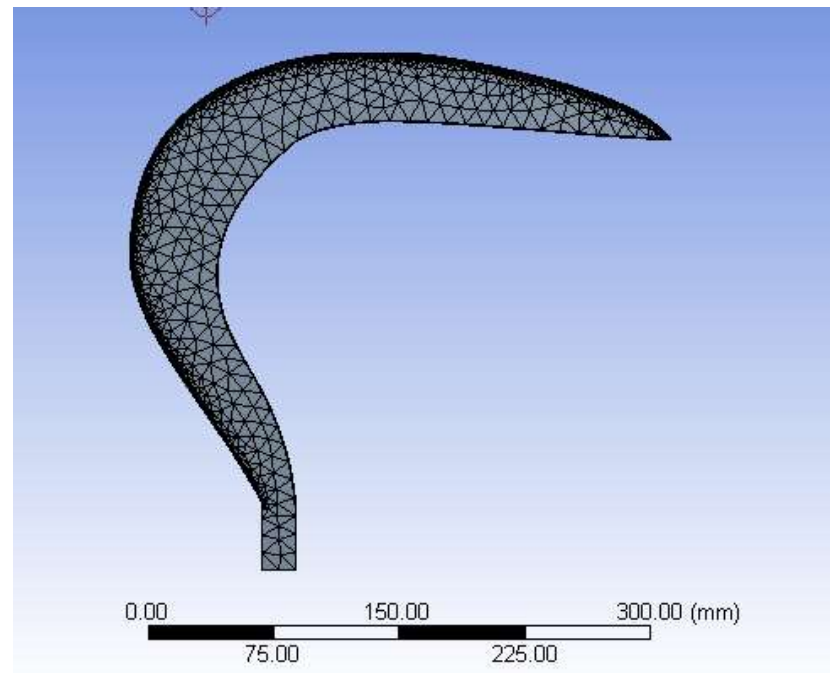

Figure 3. A CANTAS sickle after mesh generation.

Next, the specific material is assigned to the sickle design. In this simulation, material AISI 5160 high carbon steel or commonly known as spring steel is assigned to the material. This means that all of the mechanical and physical properties of the spring steel such as tensile yield and ultimate strength, density, shear and elasticity modulus and thermal expansion coefficient are pre-defined in the software. Then, the loads such as the cutting force and the fixed support are assigned to the sickle. In this case, $300 \mathrm{~N}$ of cutting force is applied to the upper sharp cutting edge of the sickle as shown in Figure 4 (Jelani et al., 1998).

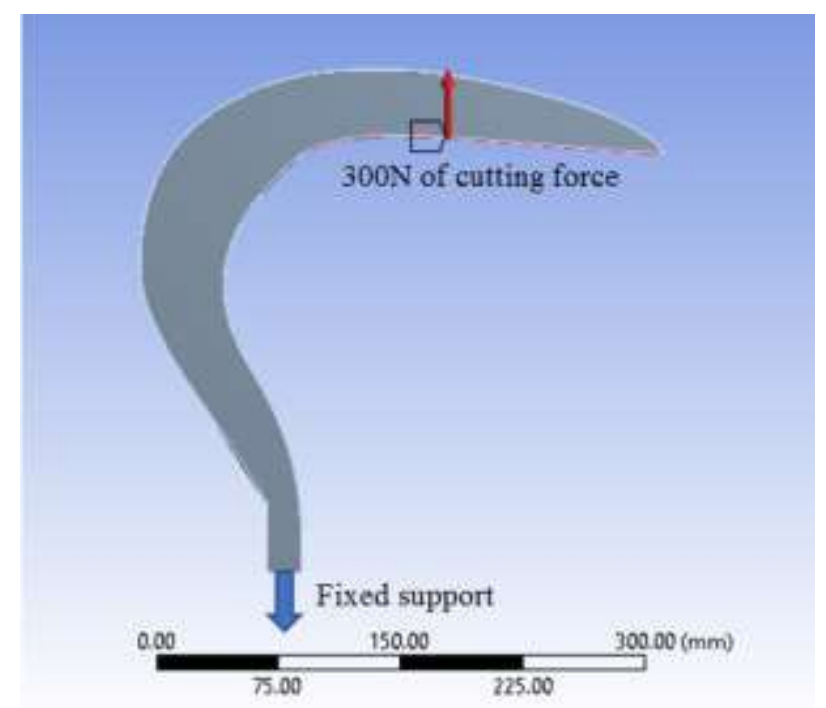

Figure 4. The loads which consist of cutting force and fixed support assigned to the sickle. 
In addition, fixed support is assigned at the bottom part of the sickle which is connected to the CANTAS gearbox. After that, the software runs the computational calculation, and the simulation of how the sickle behaves under the pre-assigned loads is served as the result. The simulation is then repeated but this time, the assigned sickle material is changed to AISI 316 stainless steel and A6061-T6 aluminum alloy respectively. The obtained results such as the design weight, total deformation under loads, stress and strain experienced by the sickle design are then compared to determine which material is the most suitable for CANTAS.

\section{Results and Discussion}

Table 2 summarizes the results obtained from the analysis. Based on the simulation done by the ANSYS software, the sickle has a total deformation of $6.42 \mathrm{~mm}$ at the end tip if spring steel is used as the sickle material. If the material is changed to stainless steel, the deformation of the sickle increases up to $6.98 \mathrm{~mm}$ which is about $8.7 \%$ increment. However, the sickle deformation has staggered much higher up to $18.94 \mathrm{~mm}$ which is more than double the increment of spring steel sickle if the material is aluminum alloy. Figure 5 shows the total deformations of each sickle based on the simulation result. In addition, Figure 6 compares the total deformation experienced by each metal under the cutting load graphically to determine the significance of the different deformation values.

Table 2. Summary of simulation results of spring steel, stainless steel and aluminum sickle when subjected under loads.

\begin{tabular}{cccccc}
\hline Material & $\begin{array}{c}\text { Total } \\
\text { Deformation } \\
(\mathrm{mm})\end{array}$ & Stress (MPa) & Strain & Weight $(\mathrm{g})$ & $\begin{array}{c}\text { Corrosion } \\
\text { Resistance }\end{array}$ \\
\hline $\begin{array}{c}\text { AISI 5160 } \\
\text { Spring Steel }\end{array}$ & 6.42 & 672 & $2.25 \times 10-3$ & 199.58 & No \\
$\begin{array}{c}\text { AISI Stainless } \\
\text { Steel 316 }\end{array}$ & 6.98 & 671 & $2.62 \times 10-3$ & 202.88 & Yes \\
$\begin{array}{c}\text { A6061 } \\
\text { Aluminum } \\
\text { alloy }\end{array}$ & 18.94 & 668 & & & Yes \\
\hline
\end{tabular}




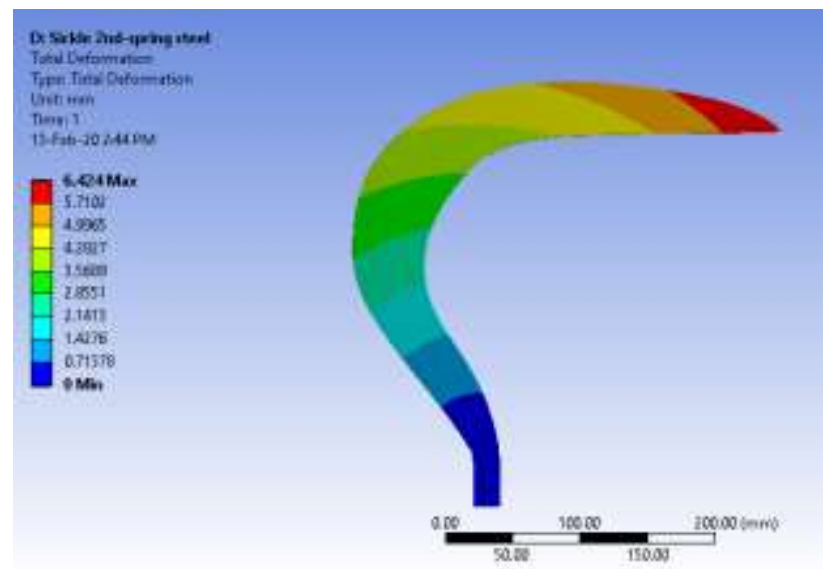

(a)

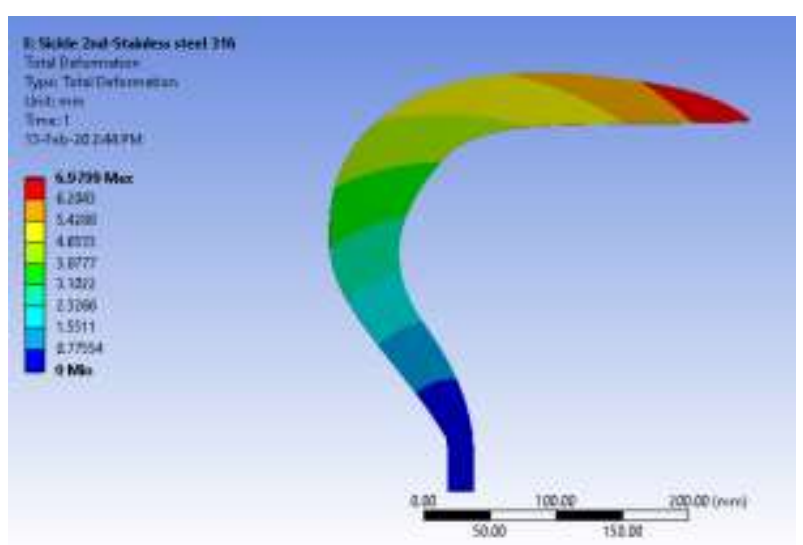

(b)

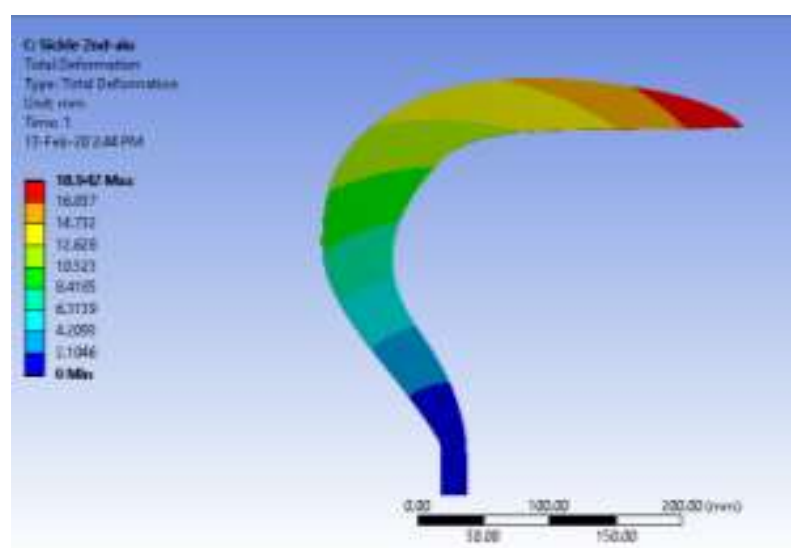

(c)

Figure 5. The sickle's simulation result of total deformation of spring steel (a), stainless steel (b) and aluminum (c). 


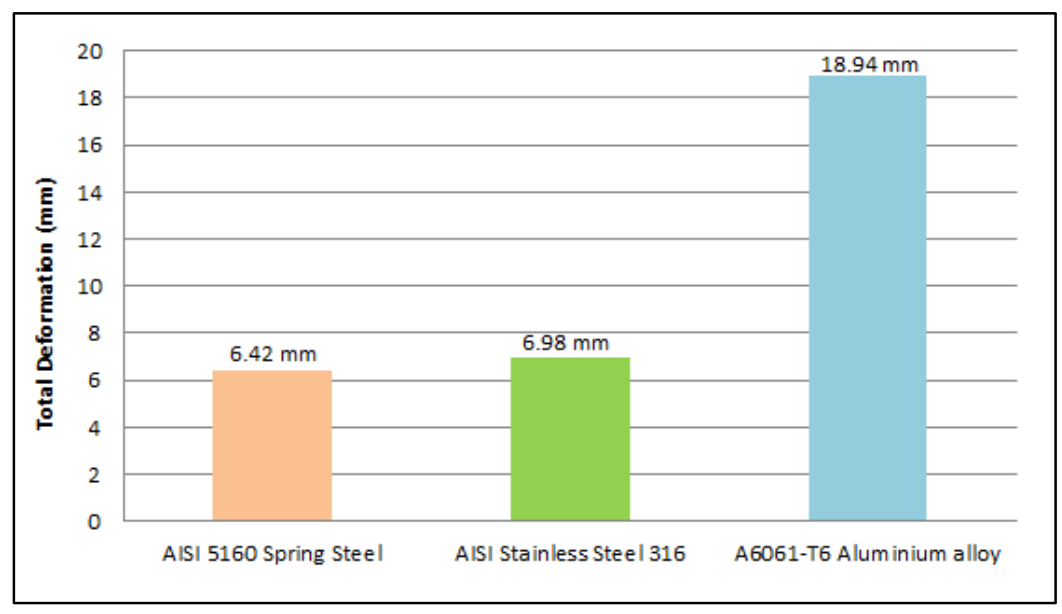

Figure 6. A graphical comparison of total deformation experienced by each metal under cutting load.

High deformation on the sickle is not favorable as it can decrease the efficiency of the cutting ability as well as cause mechanical failure to the sickle. This means that the sickle can break during its usage. As shown in Figure 6, the performance of the stainless-steel sickle in terms of material deformation only differs slightly which is $0.76 \mathrm{~mm}$ difference compared to spring steel sickle. However, the deformation of aluminum sickle differs up to 3 times the value of spring steel which makes the aluminum as unsuitable material for the sickle application.

The results of stress and strain experienced by the sickle under the assigned loads are then compared among the different materials. The sickle using spring steel material experiences $672 \mathrm{MPa}$ of stress. For the stainless-steel sickle, the stress is $671 \mathrm{MPa}$ whereas, for aluminum alloy, the stress is $668 \mathrm{MPa}$. The results of the stress and strain experienced by the sickle with different materials are depicted in Figure 7. In addition, Figure 8 shows a comparison of the values for each metal against their respective ultimate tensile strength value to determine whether the sickle structure will fail or not when subjected under the cutting force.

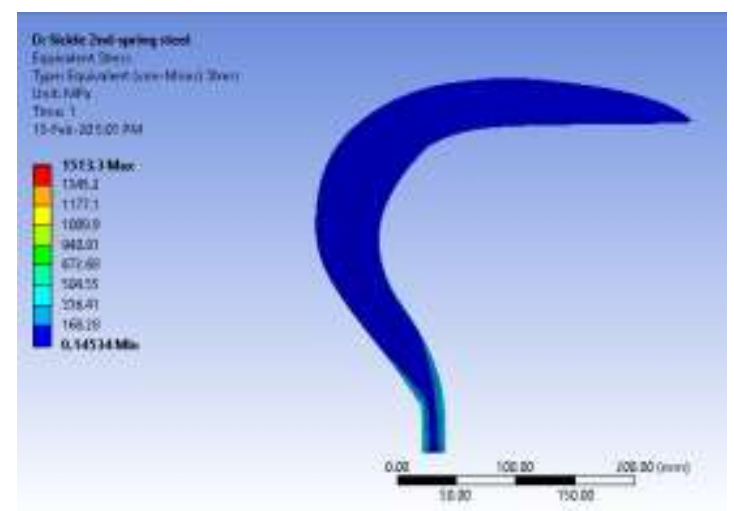

(a) 


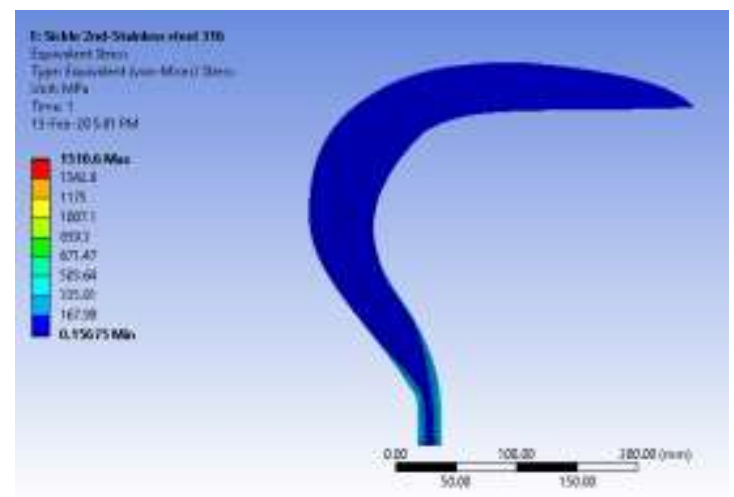

(b)

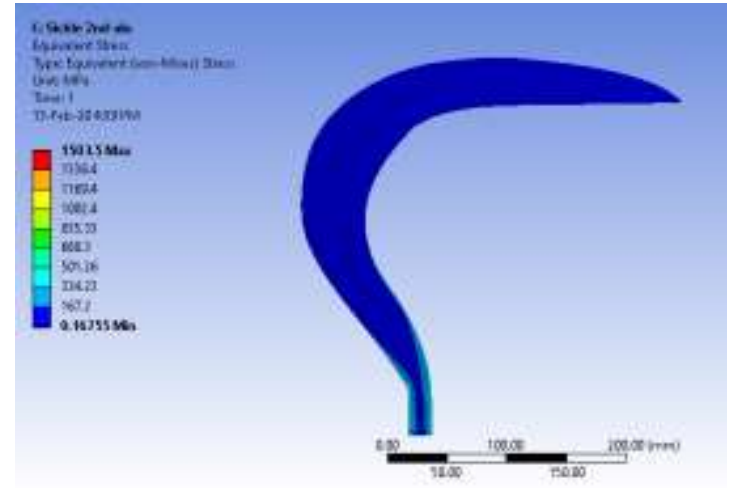

(c)

Figure 7. The sickle's simulation results of stress experienced by spring steel (a), stainless steel (b) and aluminum (c).

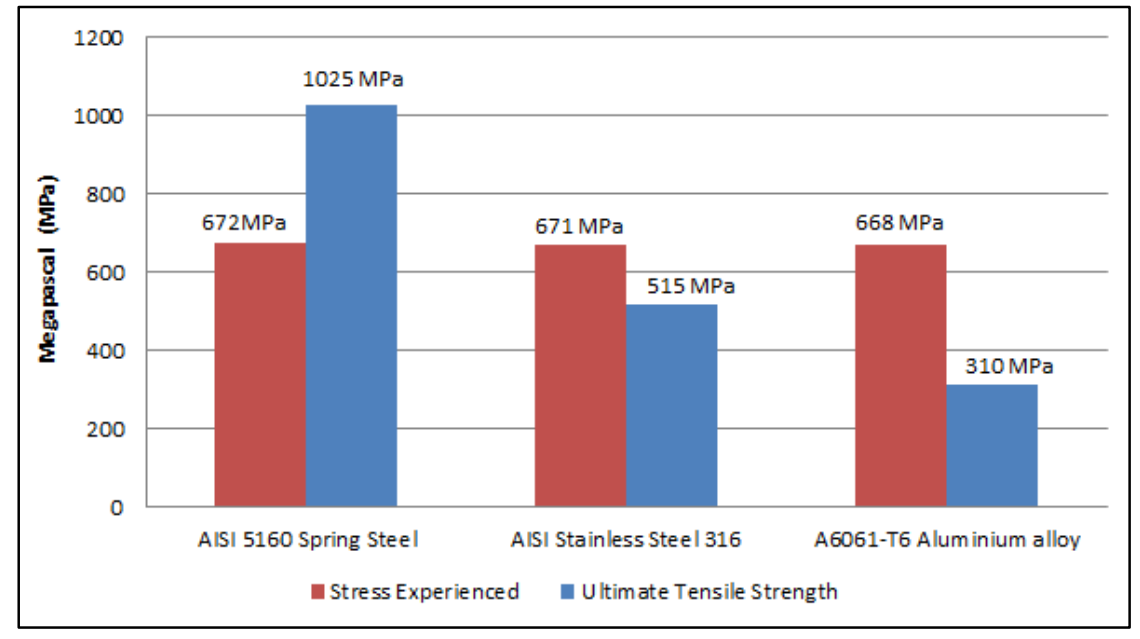

Figure 8. A graphical comparison of stresses experienced by each metal under cutting load versus the metal's ultimate tensile strength value. 
Based on the stress value, the spring steel sickle can withstand the stress because it does not exceed the material ultimate tensile strength which is $1025 \mathrm{MPa}$. As for stainless steel and aluminum sickles, the stress value experienced by each of the sickles already exceeds their ultimate tensile strength which means that the sickles will break when subjected under those cutting force and such stress. Other than that, the value of strain experienced by each of the metal is also simulated. The least strain value of the spring steel sickle means that it has the least deformation when subjected to the load of the cutting force. Figure 9 shows the simulation results for the strain experienced by each metal whereas Figure 10 compares the value of strains experienced by the metal graphically.

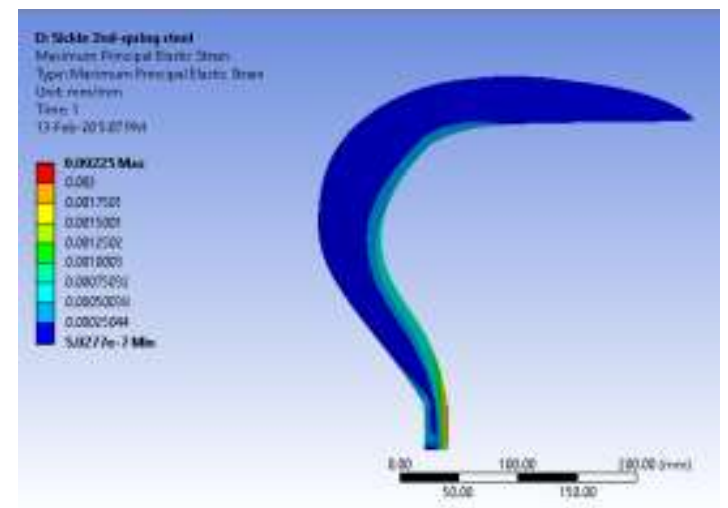

(a)

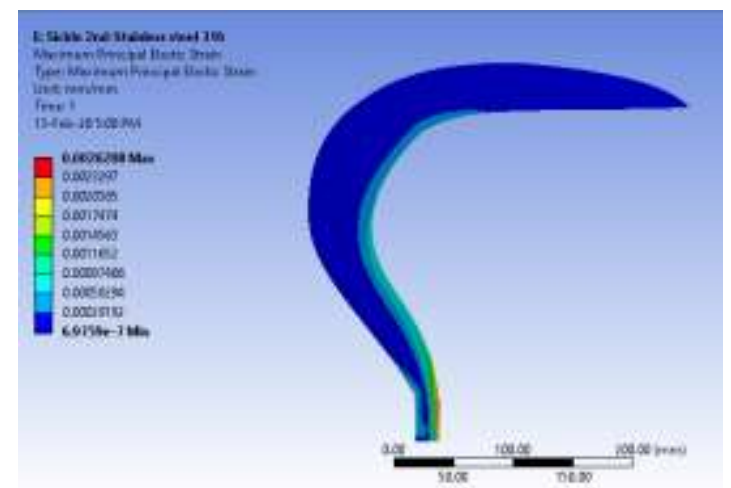

(b)

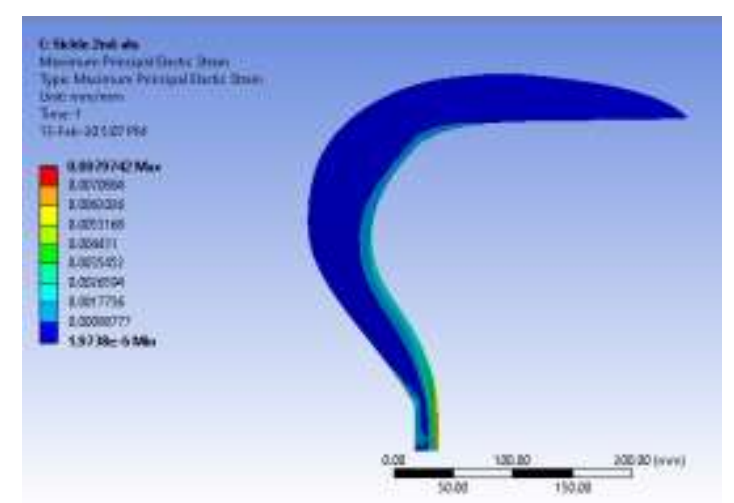

(c)

Figure 9. The sickle's simulation results of strain experienced by spring steel (a), stainless steel (b) and aluminum (c). 


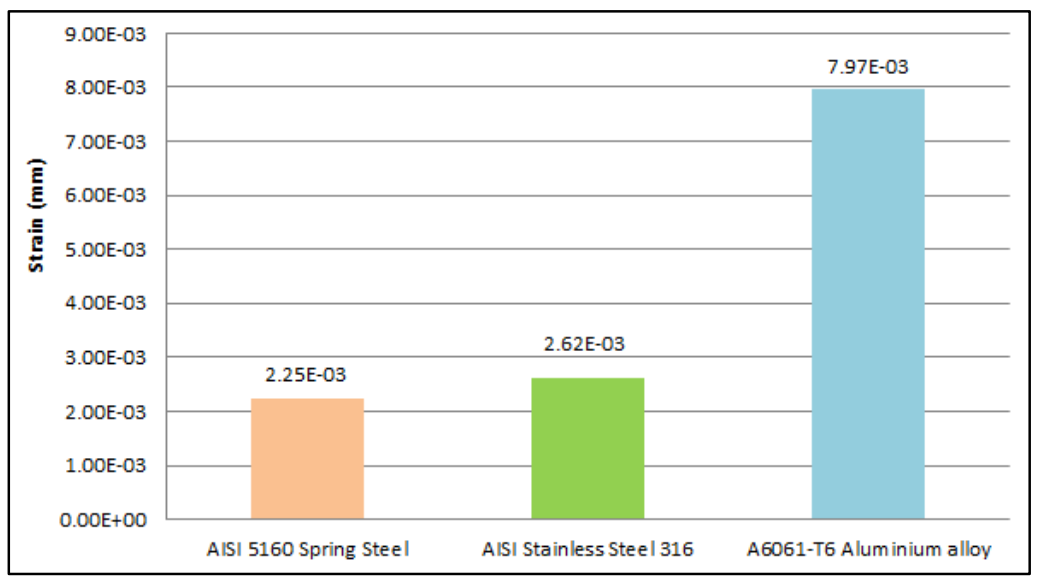

Figure 10. A graphical comparison of strain experienced by each metal under cutting load.

Based on the simulation result, the value of strain experienced by the spring steel sickle is $2.25 \times 10^{-3}$. The value of strain experienced by the stainless-steel sickle is slightly higher which is $2.62 \times 10^{-3}$ whereas the aluminum sickle has the highest strain value which is $7.97 \times 10^{-}$ ${ }^{3}$. As shown in Figure 10, the strain value of aluminum sickle is 3.5 times much higher than spring steel sickle. Thus, the performance of aluminum sickle in terms of strain experienced by the sickle is ranked as the worst compared to stainless steel and spring steel.

In addition, the weight of the sickle using different materials can be determined by the software since the density of each material is pre-defined and the software is able to determine the volume of the sickle based on its CAD shape design. Therefore, a comparison of weight can also be done to find the lightest sickle for CANTAS application. Lightweight is an important characteristic for a CANTAS sickle because its weight can produce an additional load or downward torque on the CANTAS pole. Figure 11 summarizes the weight comparison of a sickle if it is made out of these metals.

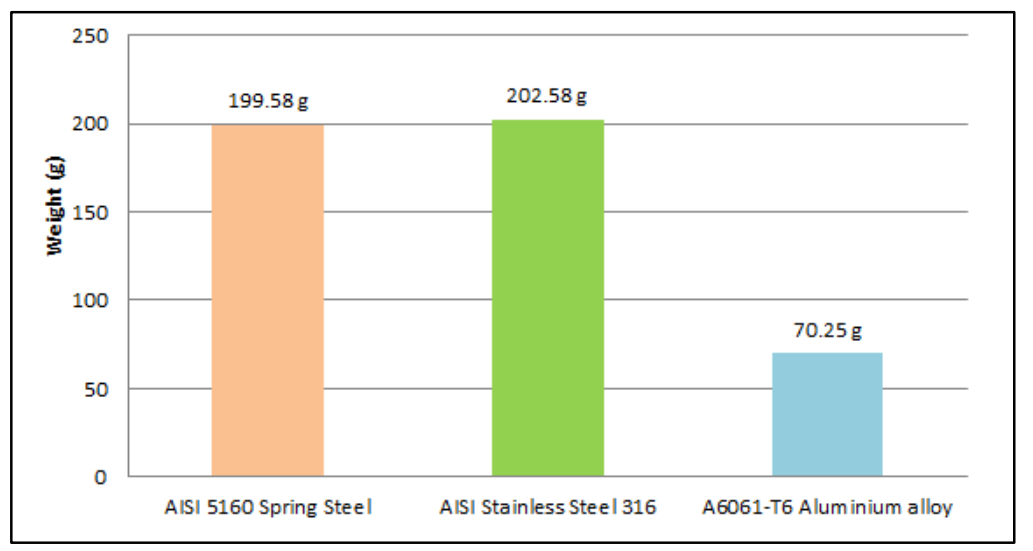

Figure 11. A graphical comparison of sickle weight with different metals.

Based on the software calculation, the weight of the sickle when using spring steel, stainless steel and aluminum are $199.58 \mathrm{~g}, 202.88 \mathrm{~g}$ and $70.25 \mathrm{~g}$ respectively. The weight of the aluminum sickle is almost 3 times lighter compared to spring steel and stainless-steel sickles. This clearly shows that a sickle using aluminum has the advantage of being the 
lightest among the 3 chosen materials. Aluminum alloy also has a corrosion-resistant characteristic which means that it does not rust. It only oxidizes and produces an aluminum oxide layer that protects the surface from further corrosion. However, aluminum cannot be accepted as a suitable material for CANTAS sickle because the material has already failed to withstand the stress and the cutting load based on the simulation result. As for stainless steel, the material also cannot withstand the stress and failed when subjected under the assigned load. In addition, the extra weight due to its density also makes it less favorable in comparison with spring steel. Therefore, the only advantage it has as a material for a sickle is the corrosion resistance characteristic.

\section{Conclusion}

The results show that spring steel material is the most suitable material to be used for CANTAS sickle. This is because of its performance under the assigned loads which can withstand the cutting force of $300 \mathrm{~N}$ without experiencing any mechanical failure based on the simulation. This means that spring steel has a higher strength compared to the other 2 metals. The stress experienced by the spring steel sickle will not compromise its structural integrity as well as its ability to withstand deformation. Other materials which are stainless steel and aluminum alloy have proved to fail and break when subjected with such cutting force since the stress value experienced by the materials exceeds their respective ultimate tensile strength value. The strain value experienced by the spring steel is also the lowest compared to stainless steel and aluminum alloy. This means that spring steel experienced the least amount of deformation and thus is more favorable as a suitable material for a CANTAS sickle. Although the corrosion-resistant characteristic and weight of spring steel sickle cannot compete against the aluminum alloy sickle, these characteristics are not the main concern for a CANTAS sickle and only serve as an additional added value for it. Therefore, it can be concluded that spring steel is the best choice of material for a CANTAS sickle if it is compared with a sickle made out of stainless steel and aluminum alloy.

Author Contributions: Conceptualization, Ahmad Syazwan Ramli and Ikmal Hafizi Mohd Azaman; methodology, Mohd Rizal Ahmad; software, Ahmad Syazwan Ramli; validation, Mohd Khairul Fadzly Md Radzi, Mohd Azwan Mohd Bakri and Mohd Ramdhan Khalid; formal analysis, Ahmad Syazwan Ramli; investigation, Ahmad Syazwan Ramli; resources, Ahmad Syazwan Ramli; data curation, Ahmad Syazwan Ramli; writing—original draft preparation Ahmad Syazwan Ramli; writing - review and editing, Abd Rahim Shuib and Salmah Jahis.

Funding: No external funding was provided for this research.

Conflicts of Interest: The authors declare no conflict of interest.

\section{References}

Harish, A. (2019, August 9). Simscale. Retrieved from: https://www.simscale.com/blog/2016/10/what-is-finiteelement-method/

Ismail, A., Ahmad, S. M., \& Sharudin, Z. (2015). Labour productivity in the Malaysian oil palm plantation sector. Oil Palm Industry Economic Journal, 15(2), 1-10.

Jelani, A. R., Ahmad, D., Hitam, A., et al. (1998). For and energy requirements for cutting oil palm frond. Journal of Oil Palm Research, 10(2), 10-24. 
Jelani, A. R., Hitam, A., \& Jamak, J., et al. (2008). Cantas ${ }^{\mathrm{TM}}$ - A tool for the efficient harvesting of oil palm fresh fruit bunches. Journal of Oil Palm Research, 20, 548-558.

Kushairi, A., Ong-Abdullah, M., \& Nambiappan, B., et al. (2019). Oil palm economic performance in Malaysia and r\&d progress in 2018. Journal of Oil Palm Research, 31(2), 165-194.

doi:10.21894/jopr.2019.0026

MakeItFrom.com. (2020). 6061-T6 Aluminum. Retrieved February 3, 2020, from https://www.makeitfrom.com/material-properties/6061-T6-Aluminum/

The World Material. (2020). SAE AISI 5160 steel, high carbon 5160 spring steel properties, composition. Retrieved February 3, 2020, from https://www.theworldmaterial.com/sae-aisi-5160-high-carbonspring-steel/

The World Material. (2020). Grade AISI 316 stainless steel, SS316 (UNS S31600) properties, density, composition, yield strength, thermal Conductivity. Retrieved February 3, 2020, from https://www.theworldmaterial.com/aisi-316-ss316-stainless-steel-properties-composition/ 